Check for updates

Plymouth

Cite this as: BMJ 2022;376:066 http://dx.doi.org/10.1136/bmi.066 Published: 11 January 2022

\title{
Covid-19: Omicron drives weekly record high in global infections
}

\section{Luke Taylor}

The number of new covid-19 infections recorded worldwide from 27 December 2021 to 2 January 2022 increased by $71 \%$ from the previous week, says the World Health Organization's weekly epidemiological report.

Some 9.5 million new cases of the disease were recorded-the highest number to date and a sharp reversal of the steady decline in weekly cases that the world has seen since October 2021. Weekly infections rose by $65 \%$ in Europe, by $78 \%$ in Southeast Asia, and by $100 \%$ in the Americas.

Maria Van Kerkhove, covid-19 technical lead for WHO's Health Emergencies Programme, said that the global spike in infections was being driven by the omicron variant, which had been detected everywhere where good genetic sequencing was available. Omicron's mutations have made it better at adhering to human cells and escaping immunity from infection and vaccination.

The surge is also the result of a decrease in social distancing, mask wearing, and avoiding crowds. "All of those factors allow viruses to spread, whether it's omicron or something else," Kerkhove told a press conference on 8 January.

Growing international evidence shows that omicron is less likely than the delta variant to cause severe disease or hospital admission. While cases increased in every region, deaths declined everywhere except in Africa, where deaths were up by $22 \%$ on the previous week, WHO data showed.

\section{Hospital capacity}

But the surge in infections is still translating to a high number of hospital admissions.

Michael Touchton, head of the University of Miami's covid-19 policy observatory for Latin America, said that several Latin American and Caribbean countries including Argentina were registering record daily infections and that their health systems were approaching capacity.

The region's rapid vaccination rate over the past six months has protected its hospitals from collapsing as many did earlier in the pandemic. Previously a key driver of global infections, Latin America is now the most vaccinated region in the world, with more than $63 \%$ of its population fully vaccinated. ${ }^{1}$

But the greater immune escape and infectiousness of omicron is starting to offset the lesser severity of illness it causes when it comes to hospitals' operating capacity. "We are seeing more people infected with milder cases of omicron, but even a smaller percentage of severe cases strains health systems when the raw number of cases is spiking," said Touchton.
Of every 100 infections reported around the world last week, around 15 were recorded in Latin America and the Caribbean. ${ }^{2}$

As in Latin America, omicron's later arrival in Asia and its slower dispersion there have delayed the variant's impact when compared with Europe. Daily infections in India began to shoot up over the past week and are now more than 10 times what they were on 1 January. India reported 179723 new cases on 10 January and 146 deaths.

Around $67 \%$ of people in India have been double vaccinated, and the government is administering booster shoes to healthcare staff, frontline workers, and people over $60 .^{3}$

The increased infectiousness of omicron is testing the strategies of countries that were global exemplars in covid-19 containment. China's government restricted travel to and from the northern port city of Tianjin on 10 January in an effort to contain the 21 new omicron infections recorded there on 9 January. ${ }^{4}$ To leave the city, residents must present approval from employers or community authorities for essential travel.

Some 13 million residents in the northern city of Xi'an-one of several major cities experiencing omicron outbreaks, which could endanger China's hopes of a smooth hosting of the Winter Olympics on 4 February-are now in their third week of lockdown. China reported 97 new cases on 9 January, up from 92 a day earlier. ${ }^{5}$

\section{Reducing exposure}

Australia, which had similarly employed strict lockdowns and tight border controls to keep covid infections close to zero earlier in the pandemic, has seen omicron accelerate the unravelling of the country's aggressive approach to containment.

Australia's total number of covid-19 infections surpassed one million on 10 January, with more than half recorded in the past week. The prime minister, Scott Morrison, has said that the country must "push through" the omicron outbreak. Morrison's government will ease isolation restrictions for workers in food production and distribution who have come into contact with someone who has an asymptomatic covid-19 infection. Some states have increased restrictions to slow the growing saturation of hospitals. $^{6}$

Senior WHO officials urged people to reduce their exposure to areas with a high risk of virus transmission and to get fully vaccinated, to prevent overcrowding in hospitals and unnecessary deaths. Health workers around the world were overstretched, they added. 
The coming months would be difficult, warned Kherkove, who said that the high circulation of the virus meant that "it is very unlikely that omicron will be the last variant you'll hear us speaking about."

1 Slattery G, Geist A. Analysis: South America is winning the global vaccination race. Reuters. 28 Dec 2021. https:/www.reuters.com/world/americas/south-america-battered-by-covid-19-nowwinning-global-vaccination-race-2021-12-28/

2 Covid-19 tracker: Latin America and the Caribbean. Reuters. https://graphics.reuters.com/worldcoronavirus-tracker-and-maps/regions/latin-america-and-the-caribbean/

3 Ministry of Health of India. Co-WIN dashboard. https://dashboard.cowin.gov.in

4 China’s Tianjin tightens control over travel after Omicron cases. Reuters. 10 Jan 2022.

https://www.reuters.com/business/healthcare-pharmaceuticals/chinas-tianjin-tightens-control over-travel-after-omicron-cases-2022-01-10/

5 China detects more Omicron cases as cities tighten restriction. France24. 10 Jan 2022.

https://www.france24.com/en/live-news/20220110-china-detects-more-omicron-cases-as-citiestighten-restrictions

6 Jose R. China detects more Omicron cases as cities tighten restrictions. Reuters. 10 Jan 2022. https://www.reuters.com/business/healthcare-pharmaceuticals/australia-covid-19-infections-hit1-million-omicron-drives-record-surge-2022-01-09/

This article is made freely available for personal use in accordance with BMJ's website terms and conditions for the duration of the covid-19 pandemic or until otherwise determined by BMJ. You may download and print the article for any lawful, non-commercial purpose (including text and data mining) provided that all copyright notices and trade marks are retained. 